\title{
Sustainable development aims for he what goals do they have to reach and where are they now? ${ }^{2}$
}

\begin{abstract}
The resources of our planet are limited. If humanity wishes to protect the Earth and leave behind a better place for the next generations than we got from our parents, a sustainable way of thinking must be involved in our everyday lives. Currently, the goal is to influence as many individuals as possible and teach them to make sustainable choices. The solution can be in our educational system. The main goal of this paper is to collect and systematize current programs, and their content in connection with HE sustainable development and introduce the associations, which support these changes. The paper will contain a SWOT assessment of Budapest Business School's sustainability strategy, and hopefully, it could become a guidance for other HEIs where to start their changes.
\end{abstract}

Keywords: sustainability, sustainable development, higher education, SWOT

\section{Acknowledgement}

This paper and the research behind it would not have been possible without the exceptional support of my interviewees, Andrea Nagy, Balázs Heidrich and Sára Csillag. With their knowledge and enthusiasm, they inspired me to write this paper and participate at the conference. Gábor Király and Zsuzsanna Géring have also read through my tran-

1 Junior Researcher at Budapest Business School, Future of Higher Education Research Center, PhD student at Budapest Business School, Doctoral School of Entrepreneurship and Business; e-mail: szendrei-pal.eszter@unibge.hu

DOI: http://dx.doi.org/10.31570/Prosp 202118

2 This paper was prepared as part of the project entitled "The future of business education" funded by National Research, Development and Innovation Office, Hungary (K127972). 
scriptions, answered my numerous questions with unfailing patience and made many insightful comments related to my work. Their generosity and expertise improved this study in innumerable ways and saved me from many errors; those that remain are entirely my own responsibility.

\section{Introduction}

Sustainability has become an increasingly important topic over the years. Many programs and conferences were organised and held all over the world in connection with this topic. The latest - and apparently the largest - program was created in 2015. This is the AGENDA 2030 organised by United Nations Educational, Scientific and Cultural Organization (henceforth UNESCO). This is an action plan created for people to submit the 17 sustainability development goals (henceforth SDGs) and 169 targets until 2030. These achievements could help balance the three dimensions of sustainable development: the economic, social, and environmental (United Nations, 2015). Although the number of goals and targets seems very high, the period of this program is 15 years, so this has to be enough to fulfil the requirements and prepare the institutions and people to go about their business in a sustainable way.

The role of education in achieving sustainable goals was noticed many years ago. The report of the United Nations Conference on the Human Environment in Stockholm, 1972 already included recommendations in connection with the educational aspects of environmental issues. Furthermore, the United Nations Environment Programme (henceforth UNEP) was founded there (United Nations, 1972). One of the UNEP's topics is education and environment, and they are still actively participating in developing the strategy of education in a sustainable way (United Nations Environmental Programme, n. d.). Additionally, according to Annex V. of the International Association of Universities 2nd Global Survey Report on Higher Education and Research for Sustainable Development, without higher education and research none of the 17 SDGs can be achieved (Mallow-Toman-Van't Land 2020). Through higher education, which is an essential part of a strong and sustainable education system, a direct impact can be made on every country, and this is why it has a very important role in the process (United Nations, n. d.).

First of all, the most important documents and associations, which can help achieve sustainability goals will be introduced. After that, skills, and personal traits, which are essential for a sustainable future, will be collected and the sustainability strategy of $\mathrm{Bu}$ dapest Business School and its SWOT assessment through interviews will be discussed 
in the paper. As a result of the paper, connections between official reports and BBS' strategy will be analysed, and it may function as an example for other institutions for realizing their sustainability aims.

\section{Most important official documents about sustainability goals and actions in the sphere of higher education}

Several documents were issued in the past few years in connection with sustainably developing education. It could be confusing for a university and they may give up their goals because of the lack of systemization of the content of these documents. The goal of this section is to introduce shortly the most important documents and their relevant parts for higher education, which hopefully could provide help in where and how to start the integration of sustainability methods into the universities processes.

\section{Final Report of Tbilisi Intergovernmental Conference on Environmental Education}

The conference was organized by UNESCO in cooperation with UNEP, in 1977. This is the first official report, which has raised attention to the connection between education and achieving sustainability goals. The main topics of the conference covered, for example, the role of education in facing environmental problems, strategies for environmental education development, and cooperation for the development of environmental education. This conference was special not only because of its educational aspect, but because of the realization, that the sources of environmental problems should not be investigated only from physical and biological aspects, but the social, economic, and technological environment must also be considered. One of the main messages of the conference was that environmental education must be a lifelong learning process, which should not be limited to the formal system according to their recommendations (UNESCO, 1978)

\section{AGENDA 21}

AGENDA 21 was created at the United Nations Conference on Environment \& Development in Rio de Janerio, 1992. This is an action plan to achieve sustainable development goals. The scope of this program was not limited only to higher education, but all areas, which help improve living standards, fulfil basic needs, protect the ecosystem 
more, and lead to a safer future. This program supports the collaboration of members, as these targets could not be achieved by any country on its own (United Nations, 1992).

Aims in connection with education can be found in Section IV. chapter 36 promoting education, public awareness, and training. There are 3 main program areas: reorienting education towards sustainable development, increasing public awareness, and promoting training (United Nations, 1992).

\section{UNECE Strategy for Education for Sustainable Development}

This strategy was created by the United Nations Economic Commission for Europe (henceforth UNECE) in 2005. According to this document, education is a human right, and it is a prerequisite for achieving sustainable development. Greater awareness and critical reflection can be provided with the help of education for sustainable development (henceforth ESD). The strategy aims to encourage members of UNECE to integrate ESD goals into the formal education system. As a result, people will be more competent and will have the necessary skills and knowledge for a sustainable future. Furthermore, they will be able to live in harmony with nature and be concerned with social values (United Nations, 2005).

\section{AGENDA 2030 - Goal 4.7}

AGENDA 2030 was issued by UNESCO in 2015. Its main goal is to realize human rights for all, ensure gender equality and empowerment of women and girls. It pictures a very ambitious future, where there is no poverty, hunger, disease, or want (UNESCO, 2015).

The role of education appears in goal 4, which is to "ensure inclusive and equitable quality education and promote lifelong learning". It aims at the transformation of lives through education. Goal 4.7 is the only one, which is relevant for a Central European university as this involves teaching knowledge and skills regarding sustainability. Education must provide a skillset and knowledge for learners to be able to promote sustainable development and sustainable lifestyles. The implementation is the main task of higher education for the next years (UNESCO et al., 2015). 


\section{Associations}

As the implementation of goals is not an easily manageable task for universities, there are several associations, which can help in the process with methodology, experience, and expertise. Through networks, universities can receive useful knowledge, which may help them achieve sustainability goals easier. In the following, two associations will be introduced shortly.

\section{International Associations of Universities}

The International Associations of Universities (henceforth IAU) was founded in 1950 with the contribution of UNESCO. IAU is a leading global association of higher education institutions and organizations, and it is one of the biggest official partners of UNESCO in associate status. It has members from more than 130 countries, and it acts as the global voice of higher education to UNESCO. The mission of IAU is to support policies and practices, which respect diverse perspectives and promote social responsibility in higher education (IAU, n. d.-a).

IAU has four strategic priorities. First is the promotion of value-based leadership in higher education. The second is remaining as a leader for inclusive, fair, and ethical internationalization of higher education. The third strategic priority is to achieve fully integrated sustainable development into higher education strategies, while the last one is the enhancement of the role of technology in higher education (IAU, n. d.-a).

Higher Education and Research for Sustainable Development (henceforth HESD) is the exact name of the third strategic priority. It aims at the realization of AGENDA 2030 goals, so they assist in sustainable development concepts and principles in strategic planning for higher education institutions. The objectives are to share experiences concerning SDGs, monitor trends and issues related to HESD, and provide training. IAU has a so-called ABC strategy, which applies in the case of HESD. "A" means advising and advocating, "B" means building synergies and networking, " $\mathrm{C}$ " means communicating and convening (IAU., n. d.-b)

\section{Principles for Responsible Management Education}

Principles for Responsible Management Education (henceforth PRME) is an initiative supported by the United Nations, founded in 2007. It has more than 800 members, and so this is the largest organized relationship between management-related higher edu- 
cation institutions and the United Nations. PRME works on the basis of six principles through which it ensures that management and business-related institutions provide the necessary skills needed to balance economic and sustainability goals, for the future leaders. Business and management schools are one of the most influential actors in the world, this is why PRME has a huge role in shaping the future (PRME, n. d.-a)

PRME Chapter Central and Eastern Europe (henceforth Chapter CEE) was established in 2016. It gathers the members of the region and serves as a platform for dialogue and collaboration. Training, where members can share their knowledge and open up new perspectives is organized annually (PRME, n. d.-b).

\section{Implementation of SDG 4.7 - Future skills and transformative learning}

Luckily, in Central Europe, only SDG 4.7 could be relevant, as the other goals in connection with education were already applied many years or decades ago (just like gender equality, the teaching of children, etc.). Although implementing only one goal does not seem challenging at first glance, it is a very complex task. On the one hand, the skills, which will be useful in the future must be determined. This requires research on the topic of sustainable skills and future skills. On the other hand, universities must assess their curricula and find a way to implement skill development and sustainability topics into it. Additionally, new teaching methods would be required in the future. In this section the most important future skills will be collected.

There are some core competencies, which will be extremely important in the future. GCED aims to equip students with them. First of all, students must have a thorough knowledge of global issues, values, like justice, equality, dignity, and respect. Then they will need cognitive skills (critical thinking, systematic, creative, multi-perspective approach) in order to recognize different angles of issues. Additionally, non-cognitive skills, like social skills (empathy, conflict resolution, and communicative skills, networking, and interacting with people from different cultures) will also be needed in the future. Last, but not least learners must behave collaboratively and responsibly for the collective good. (UNESCO, 2013.)

The collected skills are nearly the same as those in the research of Laininen (2019). Knowledge about the economy, society, humans, and nature are important to understand real-life problems and sustainability issues. Besides the mentioned skills, there are innovation skills, scientific, environmental, societal, and cultural literacy skills marked as important from a sustainable future point of view. It is important to discover and keep in mind the intuition and emotions of a learner, as intentional intuition, creativ- 
ity, unlearning, and emotional intelligence are equally important in the future. Change agents will have a big responsibility in changing the ecosystem, so mindfulness, courage, resilience, curiosity, ethics, sufficiency, planetary responsibility, and leadership should be encouraged and fostered by the education system. The effects of influencing students can be huge. As the levels of learning and change show, the process always starts at the level of the individual. After that, individuals can influence organizations, and finally, organizations could change the whole ecosystem (Laininen 2018).

The teaching of these skills requires new teaching methods. Besides problem-based and contextual learning, the definition of transformative learning also appears. The main point of transformative learning is not to focus on subjects or sciences during the teaching process, instead, the centre of knowledge is the wholeness of the world and lives. It can transform the understanding of humanity, wellbeing, and the role of the economy in our world and daily lives. This method questions the role of currently existing curricula, as it usually accumulates outdated knowledge, instead of providing learning opportunities (like the latest scientific results). In order to achieve sustainability goals in the future, implementing transformative learning should be the core mission of universities (Laininen 2018).

The exact role of universities is still not clear, but their part in achieving sustainability goals is unquestionable. Maybe the key is not in future skills teaching and transformative learning, but regardless of the educational system we must show the core values of a sustainable future for their students (Laininen 2018).

The main goal of SDGs is not a simple implementation of these skills into the curricula or changing education as the way they determine. It is to encourage universities to come up with new ideas by themselves and help universities to find their own way to a sustainable future.

To show an example of how to achieve sustainability goals in practice and how to perform changes in connection with sustainability, the sustainability strategy of $\mathrm{Bu}$ dapest Business School and its SWOT assessment will be introduced in the next part.

\section{Sustainability at Budapest Business School}

Sustainability was always important for Budapest Business School (henceforth BBS), but since 2016 it has played a key role in the University's life. The first strategy was created in 2017, and since then many changes for sustainability have been performed. Its goal is to make an impact on the community of the University and operate in a more sustainable manner. Students' understanding of the importance of organizational sustainabil- 
ity and responsibility is indispensable. With the help of the knowledge gained, they can become more responsible citizens, employees, and leaders of the future. Additionally, building a sustainability-related social network can ensure the flow of knowledge about sustainability. The long-term objective of the University is to become a regional leader in sustainability. This is how BBS acts for a Better Future. (BBS, n.d.-a). BBS's goal is to operate as a socially responsible and sustainable university. In the introduction of the University sustainability also appears as a traditional value (BBS, n. d.-b).

\section{Sustainability strategy}

The period defined by the strategy was between 2017 and 2020, which overlaps the period of the Institutional Development Plan. This is the most important plan of University; all strategies must follow this. As this is the first sustainability strategy of BBS, these first three years were marked as a period of learning. The long-term goal of is to set up a new organizational culture and became a regional leader in sustainability (BBS, 2017).

There are 4 focus areas included in the strategy:

- responsible education and responsible research,

- development of an internal community,

- relations with external stakeholders,

- responsibility for the natural environment (BBS, 2017).

The responsible education and responsible research focus point is in connection with BBS' core business, which is education and research. The main aim of this focus point is to integrate sustainable and responsible behaviour in the curricula, individual subjects, and research programs. Thanks to this, students will be able to solve responsibility-related problems and implement sustainability principles (BBS, 2017). The main results of responsible education in the last three year were the upgrading of the curricula and the integration of a mandatory subject about sustainability (University Sustainability Centre [USC], 2020). In connection with research, the ISSUE (Innovative Solutions for Sustainability in Education) project was the biggest event of the period. This project started on 1st November 2018 and will end on 30th April 2021. Participants of this project came from both the academic and non-academic sectors. Universities are from a very wide range, as besides BBS, universities joined from the UK, Slovenia, Germany, and Finland. The aim of this project is the development of 
educational tools, which are based on principles and goals of sustainable development (BBS, n. d.-c). Adapting these tools in higher education institutions is also a part of the main objective (BBS, 2017).

Developing an internal community affects the whole community, including students, instructors, managers, and associates working in the functional and servicing organizational units. To achieve this goal, active participation of members is required, in order to create a cooperative, supportive, and creative atmosphere at the institution. New joiners (both students and associates) must be informed about sustainability initiatives as soon as possible. There are six areas included: health, security, and welfare; strengthening the BBS community; supportive organizational culture; performance review; developing individual skills and abilities; preparation and update of institutional support documents (BBS, 2017). There were many events organized and actions taken to develop the internal community and raise the awareness of the members of the organization, e.g., voluntary day, recyclable cups on bigger events organized by BBS to reduce waste and the drawing up of the PRME report. Additionally, the Code of Ethics was also drawn up and promoted (USC, 2020).

Relations with external stakeholders mean network building with external stakeholder groups based on the principle of sustainability. This is an option for sharing experience and knowledge about sustainability and a chance for learning from other institutions (BBS, 2017). Membership in PRME and participation in the CEE chapters in Slovenia and Budapest, and participating in a conference about sustainability organized by NIBS (Network of International Business Schools) were some of the activities from the past three years in connection with this focus area (USC, 2020).

Responsibility for the natural environment is also important for BBS, as daily activities could be harmful to the environment. The goal of this focus point is to reduce the negative effects of the activities on the natural environment (BBS, 2017). In order to achieve this goal environmental investments, waste management, caring for green areas, and promoting conscious lifestyles are in focus. The main activities in connection with this focus point are solar panel investments, putting out bird feeders, and joining the Greenmetric international measuring system for universities (USC, 2020).

I believe it is important to introduce the three units, which were founded in connection with the Strategy. The main goal of the University Sustainability Centre is to manage tasks in connection with sustainability goals and connect the other two units. The task of the University Sustainability Council is to monitor the achievements of sustainability activities, while the task of the University Sustainability Network (henceforth USN) is to track projects and share best organizational practices (BBS, 2017). As the 
University Sustainability Centre is in the middle of the process, its tasks and function will be introduced in more detail below.

\section{University Sustainability Centre introduction}

The University Sustainability Centre (henceforth USC) was founded as part of BBS' first sustainability strategy in 2017. The existence of this independent unit is unique in the region. Its main task is to support and help implement into practice the goals of the sustainability strategy (BBS, n. d.-d). Furthermore, it is functioning as a "secretariat" of the University Sustainability Council, and University Sustainability Network. It is the USC's responsibility to organize and support continuous internal education, seek funding sources, maintain relevant regulations, set up budgets, and prepare reports for the University's decision-makers and their forums (BBS, 2017). The current leader of the office is Andrea Nagy (BBS, n. d.-e).

As can be seen in connection with the examples of strategic focus areas, many programs and actions were organized and performed through USC in the past three years. These mentioned activities were only a few examples from the long list of USC's full activities, much more was performed (USC, 2020). To sum up, USC is a useful unit of the University, it can support achieving goals of the sustainability strategy.

\section{Interview results}

To obtain information about the current state of BBS sustainability strategy, interviews with experts were conducted. The interviewees were Balázs Heidrich, Rector of Budapest Business School, Sára Csillag, Dean of Faculty of Finance and Accounting, and Andrea Nagy, Leader of University Sustainability Centre. The elements of the SWOT matrix are based on their answers, and so the results of the interviews will be introduced in the logic of the matrix itself.

\section{SWOT analysis of BBS's sustainability initiatives}

\section{Strengths}

In BBS there is a strong focus on sustainability. Since 2016 sustainability development became one of the most important areas in the University. BBS has separated a budget for implementing sustainability projects, which is very rare in the region. The goals of 
the Institutional Development Plan can also be connected to BBS's sustainable development strategy. Furthermore, the management supports the achievement of sustainability aims, and they are committed to supporting the integration of a sustainable way of thinking into the University's everyday life.

USC is also unique in the region, as it works as an independent unit in the University. Through the office, many programs and activities were performed, which helped the University improve its sustainability. Unfortunately, there have been many other events, programs, and other kinds of activities, which could not be finished because of different reasons. Although it does not seem positive at first glance, it shows, that the USC exerted much more effort than the successfully managed programs required.

The role of colleagues is very important in achieving sustainability aims. First of all, the creation process of the strategy was opened for everyone to reveal as many viewpoints as possible. The success of the strategy is based on the voluntary involvement of members of BBS, as they could manage their own projects and implement their own ideas. There is no pressure and order from the management, everyone should take the first step by themselves. This is the way the strategy would like to improve sustainability thinking in the organization. Additionally, the performance assessment of colleagues contains aspects, which are about the connection between their work and sustainability goals. The stronger the connection, the better the performance is rated by University management.

The curriculum was reformed in 2017, and during this process sustainability aspects were in focus. Thanks to this, a new subject was added to each program's curricula, in which students can learn how to manage and what a responsible and sustainable company should look like. The number of subjects, which include sustainability in its syllabus was also increased in the past 3 years.

International connections are also important for BBS to learn from other universities about sustainability and share their experience with other members. Therefore, BBS is a member of several international networks (e. g., PRIME, NIBS), and participated in several conferences in the past few years. Participation in the ISSUE project is also a great chance to develop the BBS sustainability strategy, strengthen the connection with other universities, and become recognized by other actors of higher education in the area of sustainability. 


\section{Weaknesses}

Sustainability thinking is not yet built into the everyday life of the University. Most of the colleagues still do not think of it as a "must-have" thing, they still consider it as an option. This may be so because of the lack of activities to raise their awareness. When the University Sustainability Centre started in 2017, there was no campaign, only highlevel units were informed about the foundation. Most of the faculties and departments (and so the colleagues there) did not know about its the role. The fact, that faculties are working and thinking completely separate from each other makes the work of USC harder, as organizing a program for the whole community is almost impossible. Each faculty requires individual programs on their own campus in order to bring sustainability closer to students, as they are not willing to travel to another campus because of an event.

USC is currently operating with only one member instead of two. This causes human resources problems, e. g., the manager of USC is the same person as the president of USN. These roles should be separated. This could be the reason why the website of USC has not been recently updated. There are many impulsions, events, and upgrades in connection with sustainability, but these are not communicated as a part of a process.

As sustainability strategy is marked as a bottom-up process, its implementation is highly dependent on the staff. They are affected by different factors, like too much administrative burden and rigid methods and processes, which slow down the implementation of their ideas. These pose significant risks, as the first one could cause fluctuation in their motivation depending on their current tasks, while in the latter case there is a chance of their losing interest in the changes because they do not have enough energy to carry through their ideas needing so many steps. These may be the reasons why there is a low interest in the topic on the lower levels of the organization.

\section{Opportunities}

As of 2021, a new strategy will be implemented, and current experiences must be considered before the planning. One of these is the idea of hybrid strategy planning. This means a mixture of bottom-up and top-down planning. Bottom-up is important to increase the interest of lower levels in the topic, and to show the members of the organization, that sustainability will always be important for BBS. Top-down is necessary, because there must be some bigger goals, which have to be implemented, and managed from higher levels, like high-volume sustainability projects, which require more 
resources, time, and energy from the organization. After creating a new strategy, it must be promoted to a wider public than the first strategy was. A successful campaign could serve as a basis for the success of the next period. Furthermore, a new website with a lot of information about sustainability will be launched soon.

Network building still ranks high on the importance list, as sharing knowledge and experiences could be a huge help in improving sustainability development. As online teaching is becoming more and more accepted, collaborations with companies, which were not successful before because of the physical limits, can be carried out now, as guest lecturers could give their lecture from anywhere. Additionally, networking could be a great chance for BBS to procure a leading role in sustainability in the region (e. g., become the most developed University in terms of sustainability issues in Central and Eastern Europe).

As for curriculum design, the current initiatives are quite promising, but further improvements must be continued in the future. The sustainability topic appears in the syllabus of about $5 \%$ of the relevant classes at BBS, but it could and should be expanded in the next few years. Implementation of transformative learning elements into the curricula of the programs of BBS could improve students' knowledge about sustainability, and additionally, they can master skills, which will be important in the future.

Reducing administrative burdens on colleagues could create enough free time, which they could use for achieving sustainability aims. Process assessment and improvement can be a solution. This means interviews would be performed with workers, who can provide information about the exact processes and methods applied by their department, and then these processes would be assessed by experts and suggestions made for an effective way to perform their jobs. This way processes would be faster, teachers would have less administrative tasks, so they could save some time. Additionally, there would be trainings for colleagues about the importance of sustainability. Their attitude could take a different turn if they had the energy and motivation for such things and it was not another mandatory task.

\section{Threats}

One of the biggest threats to achieving sustainability targets is obviously COVID-19. It influenced the strategy from many aspects, e. g., there were no resources, place, time, and energy for sustainability idea implementation, as the adaptation of new teaching methods steered away the necessary resources from it. Teaching in virtual platforms can solve the problem of teaching during the pandemic, but unfortunately, programs in 
connection with sustainability require personal attendance. Without personal contacts, promoting sustainability is hard, this is why there were no events organized by USC in the last 8 months.

The passive attitude of colleagues in relation to sustainability was typical even before Covid-19 and remained so during the pandemic. It means, they are not willing to come up with their own ideas, they just want to do their jobs and nothing extra. This is a very big risk for the sustainability strategy, as a relevant part of it depends on the actions of the members of the organization. Furthermore, people cannot really believe, their idea will be supported by the management, so they are afraid to put forth their suggestions, and even if they were willing, they do not know how to do it. This method is not usual; therefore, it requires more time than the top-down version, but once it starts working, people will be engaged in the topic. However, this cannot be achieved by force, it requires time and patience on the part of the organization.

The success of the strategy also greatly depends on the members of USN, as they are operating voluntarily. They do their tasks when they have time and they do not get paid for it. However, they can include this activity in their performance assessment, still, their motivation is fluctuating.

Finally, bureaucratic methods could harm the strategy, as they are rigid and slow. There is too much administration, which takes time from other activities, like upscaling sustainability initiatives. The problem is the obduracy of old organizational practices and methods. As colleagues are afraid of new solutions, they do not trust the effectiveness of new ways, and they are just doing things by the old, rigid methods. This could be demotivating for an enthusiastic person too, and there is a risk of not starting a project or closing it without results because of the perceived resistance of the system.

\section{Conclusion}

Official documents do not include exact rules or instructions about the implementation process of SDG 4 goals. Each university has the right to shape and expand the suggestions as they wish. Giving exact instructions, which must be applied in all universities would be a failure, as sustainability is not something which could be applied only one way. The goal of the introduced documents is to show the importance of the topic and raise the awareness of the universities about sustainability and achieve targets at their own pace and in their own way.

However, Adams et al. (2018) created a framework for university culture and sustainability through the case of the University of Worcester. Similarly to BBS, they also 
believe, that sustainability goals can be achieved through individuals, who behave sustainably. They also stated, sustainability must be part of the organizational culture. As it can be seen in the article by Adams et al. (2018) and the currently introduced SWOT assessment, changing an existing culture is a very time-consuming process, and it cannot be forced. The University of Florence also accepted the sustainability challenge, and they aim to become a green university. Fissi et al. (2021) investigated their applied practices, and among other things, they discovered that the support of management is essential. Their rector is strongly supportive of this process- just as the rector of BBS is. It seems there are some obligatory elements of the process, like enthusiastic individuals and engaged management, which any university should have if they wish to become sustainable. Discovering further mandatory aspects could be the topic of a future research.

Additionally, it is important to mention that there is a hierarchy among SDGs, and they cannot work independently from each other. According to Szennay et al. (2019), a target can be linked to several goals. Therefore, focusing on the development of SDG 4 can help achieve other SDGs too.

In order to achieve the set sustainability goals, joining organizations could be useful for any higher educational institution, as conferences and projects organized by them could provide useful knowledge and practices about the implementation of sustainability methods. It can be seen from the example of BBS that sharing, and receiving knowledge about sustainability can help in networking, and the University could gain a reputation in the region. Furthermore, we should take into consideration not only the activities of associations and other universities, but high schools could also show good practices for sustainable development. The article by Gamarra et al. (2019) introduces a high school case study, in which they conclude, that the negative impacts on the environment and costs related to human health, crops, biodiversity materials and global warming can be decreased through the identification and analysis of key activities.

As the University both tried their own methods and used the suggestions of associations, their status of achieving the sustainability goals set forth by UNESCO seems outstanding in the region. The internal community development and responsible education goals of BBS' sustainability strategy includes activities which can be connected to SDG 4.7, as this deals with the development of individual skills and abilities, and curricula upgrade. The "Responsible and sustainable company" course is mandatory for each student at the University. With its help, students can form a basic knowledge about sustainability and a skillset for responsible thinking, but with only one subject the sustainable behaviour of students cannot be completely developed. Further implica- 
tions of sustainability topics are required to related subjects to shape students' thinking and thus shape the future of our lives. At the Tbilisi conference it was also highlighted, that environmental education should not be just a subject, it must be incorporated into each programme. My interviewees claimed that BBS' goal is to incorporate sustainability topics into each relevant subject. This aim will be part of the next strategy. Thus BBS will be in line with the AGENDA 2030 requirements, moreover, the University performed and will perform many other changes in the name of sustainability. Thanks to this attitude, it is possible to become a regional leader in sustainability and reach long-term goals.

The performed SWOT assessment can confirm this statement, but unfortunately, this method has some disadvantages. For example, the results could be influenced by subjective viewpoints and opinions. The results of the interviews contained some contradictions in connection with negative influencing factors of colleagues' voluntary participation in sustainability projects. The reason could be the different positions of the interviewees, as members of the organization could see a problem from divergent points of view depending on their place in the organization.

BBS's sustainability strategy and the assessment of its progress can be an example for universities similar to BBS. They could perform these steps and create self-assessment to clarify for themselves their status whether their current actions and processes are heading to a sustainable future or not. After that, they could answer the question: What goals do they have to reach and where are they now?

\section{References}

Adams, R. - Martin, S. - Boom, K. (2018). University culture and sustainability: Designing and implementing an enabling framework. Journal of Cleaner Production, 171, 434-445. https://doi.org/10.1016/j.jclepro.2017.10.032

Budapest Business School (2017). Sustainability Strategy 2017-2020. Retrieved from October 21, 2020, from https://en.uni-bge.hu/Root/Sites/BGF/tartalmak/BBS Sustainability-Strategy 2017-2020.pdf

Budapest Business School (n. d.-a). BBS for a better future. Retrieved October 22, 2020, from https://en.uni-bge.hu/BBS-for-a-Better-Future

Budapest Business School (n. d.-b). Introduction. Retrieved October 22, 2020, from https://en.uni-bge.hu/About-Us/history 
Budapest Business School. (n. d.-c). ISSUE - ERASMUS+Strategic Partnership Project. Retrieved October 25, 2020, from https://en.uni-bge.hu/International-projects/is$\underline{\text { sue }}$

Budapest Business School. (n. d.-d). University Sustainability Centre. Retrieved October 23, 2020, https://uni-bge.hu/szervezetiegysegek/rektoratus/FenntarthatosagiKozpont

Budapest Business School. (n. d.-e). Colleagues. Retrieved October 23, 2020, https:// uni-bge.hu/szervezetiegysegek/rektoratus/Fenntarthatosagi-Kozpont/Munkatarsak

Fissi, S. - Romolini, A. - Gori, E. - Contri, M. (2021). The path toward a sustainable green university: The case of the University of Florence. Journal of Cleaner Production, 279, 123655. https://doi.org/10.1016/j.jclepro.2020.123655

Gamarra, A. R. - Herrera, I. - Lechón, Y. (2019). Assessing sustainability performance in the educational sector. A high school case study. Science of the Total Environment, 692, 465-478. https://doi.org/10.1016/j.scitotenv.2019.07.264

International Associations of Universities (n. d.-a). Vision \& Mission. Retrieved October 20, 2020, from https://www.iau-aiu.net/Vision-Mission

International Associations of Universities. (n. d.-b). IAU in action. Retrieved October 20, 2020, from https://www.iau-hesd.net/contenu/139-iau-action.html

Laininen, E. (2018). Transforming Our Worldview Towards a Sustainable Future. Sustainability, Human Well-Being, and the Future of Education, 161-200. https://oi. org/10.1007/978-3-319-78580-6 5

Mallow, S. - Toman, I. - Van't Land, H. (2020). Higher Education and the 2030 Agenda: Moving into the "Decade of Action and Delivery for the SDGs". IAU 2nd Global Survey Report on Higher Education and Research for Sustainable Development. ISBN: 978-92-9002-209-1.

Principles for Responsible Management Education (n. d.-a). What is PRME? Retrieved October 31, 2020 from https://www.unprme.org/about

Principles for Responsible Management Education. (n. d.-b). About the PRME CEE Chapter. Retrieved October 31, 2020 from https://www.unprme.org/chapter/prmechapter-cee

Szennay, Á. - Szigeti, C. - Kovács, N. - Szabó, D. R. (2019). Through the Blurry Looking - Glass SDGs in the GRI Reports. Resources, 8(2), 101. https://doi.org/10.3390/ resources 8020101

United Nations Educational - Scientific and Cultural Organization - United Nations International Children's Emergency Fund - World Bank - United Nations Fund for Population Activities - United Nations Development Programme - United Na- 
tions Women - United Nations High Commissioner for Refugees. (2015). Incheon Declaration and SDG4 - Education 2030 Framework for Action. World Education Forum, Incheon, Republic of Korea, 19 - 22 May 2015.

United Nations Educational, Scientific and Cultural Organization. (2013). Outcome document of the Technical Consultation on Global Citizenship Education: Global Citizenship Education - An Emerging Perspective. UNESCO's Division of Education for Peace and Sustainable Development. Paris.

United Nations Educational, Scientific and Cultural Organization. (1978). Intergovernmental Conference on Environmental Education. Organized by UNESCO in cooperation with UNEP. Tbilisi (USSR), 14-26 October 1977. Rep. No. ED/MD/49. Paris.

United Nations Environmental Programme (n. d.). Education strategy. Retrieved October 22, 2020, from https://www.unep.org/explore-topics/education-environment/ what-we-do/education-strategy

United Nations (1972). Report of the United Nations Conference on the Human Environment, Stockholm, 5-16 June 1972, New York: United Nations.

United Nations (1992). AGENDA 21. United Nations Conference on Environment \& Development. Rio de Janeiro, Brazil, 3 to 14 June 1992. United Nations Division for Sustainable Development.

United Nations (2005). UNECE Strategy for Education for Sustainable Development. High-level meeting of Environment and Education Ministries. Vilnius, 17-18 March 2005. Rep. No. CEP/AC.13/2005/3/Rev.1. Economic and Social Council. United Nations.

United Nations (2015). Transforming our world: The AGENDA 2030 for sustainable development. United Nations. New York: UN Publishing.

United Nations. (n. d.). Education - United Nations Sustainable Development. Retrieved from https://www.un.org/sustainabledevelopment/education/

University Sustainability Centre. (2020). Sustainability Network 2017-2019. Internal BBS report: Unpublished. 